\title{
UMA RELAÇÃO ENTRE AS POSIÇÕES-SUJEITO CATADOR/ESCRITOR PARA/EM TEREZA
}

Aline Rockenbach Calderaro*

\section{Introdução}

O lançamento de um livro de poemas intitulado Catando Cidadania, por Tereza Moraes Marques da Silva (uma catadora de materiais recicláveis) fez despertar nosso interesse. Intrigou-nos o fato de um sujeito muitas vezes excluído de nossa sociedade inserirse na história de uma cidade justamente dessa maneira. Portanto, neste trabalho, tomamos por objeto de estudo fragmentos de dois poemas de Tereza e duas entrevistas realizadas com ela à época do lançamento (durante a última Feira do Livro da cidade de Santa Maria, no Rio Grande do Sul), e selecionamos, para proceder à nossa interpretação, alguns enunciados da entrevista que se relacionam a questões da história de vida pessoal e profissional dessa catadora/escritora. Tais enunciados foram assim "recortados" por entendermos que, ao falar de si, Tereza se significa. Recorte, aqui, entendido como "unidade discursiva" e esta, por sua vez, como "fragmentos correlacionados de linguagem-e-situação" (Orlandi, 1984: 14).

O enfoque principal está nas relações sociais desse sujeito, uma vez que entendemos ser impossível ignorá-las no que toca ao lançamento de Catando cidadania. Restringimos nossas inquietações a uma questão que, ao nosso ver, "suplica" resposta: como se dá a relação entre as duas "identidades" de Tereza (catadora/escritora) e como elas se interpenetram, significam e (re)significam para/em Tereza?

Em nosso entender, conseguiremos compreender como os sentidos são constituídos, ideologicamente, para/no sujeito catador/escritor Tereza e como esse sujeito se inscreve na história e passa a significar diferente para ele mesmo. É importante levarmos em consideração o momento histórico em que as entrevistas foram construídas, uma vez que o interesse em interpretá-lo está estreitamente ligado a esse momento.

* Graduada em Letras pela UFSM. 
Hoje em dia, uma das cenas mais comuns que podemos presenciar é a circulação de catadores de materiais recicláveis pelas ruas das cidades, principalmente nos grandes centros urbanos, 0 que, muitas vezes, passa despercebido por nossos olhares. Mas, ao atentarmos para esse fato, percebemos que "catar" virou profissão em nosso país, não uma profissão reconhecida, mas, indiscutivelmente, fonte de sustento para várias famílias brasileiras. Num contexto em que o desemprego e a fome estão constituídos como as maiores misérias de nosso país, catar materiais recicláveis tornou-se uma, senão a única, opção para aqueles que não têm oportunidade de estudar.

O poema de Régis Bonvicino que segue abaixo vem ilustrar o "lugar" do lixo em nossas cidades:

\section{O Lixo}

plásticos voando baixo

cacos de uma garrafa

pétalas

sobre o asfalto

aquilo

que não mais

se considera útil

ou propício

há um balde

naquela lixeira

está nos sacos

jogados na esquina

caixas de madeira

está nos sacos

ao lado da cabine

telefônica

o lixo está contido

em outro saco

restos de comida e cigarros

no canteiro, sem árvore,

lixo consentido

agora sob o viaduto

onde se confunde

com mendigos 


\section{Desenvolvimento}

O conceito de discurso, na perspectiva da Análise de Discurso, "é efeito de sentidos entre locutores", como coloca Orlandi (2003: 21). Portanto, devemos "ver" o discurso não como mera transmissão de informações, mas como o "lugar" em que os sujeitos se constituem e os sentidos são produzidos, não esquecendo que "a produção do discurso é simultaneamente controlada, selecionada, organizada e redistribuída", como afirma Foucault (Foucault, 2001: 89 ). Isso significa dizer que o discurso é, de certa forma, instituído em uma dada formação discursiva dependendo das condições de produção de discurso e de sujeito. De acordo com Orlandi (2003: 30), as condições de produção podem ser consideradas em dois sentidos. Em seu sentido estrito, relacionam-se às circunstâncias da enunciação, ao contexto imediato, enquanto que, em sentido amplo, têm a ver com o contexto sócio-histórico, ideológico. No caso de Tereza, temos como contexto imediato o lançamento de seu livro, que está inserido em uma situação histórica particular - momento em que se institui a profissão catador - contexto sócio-histórico (contexto amplo). Em relação à formação discursiva, Pêcheux (1997: 160) define como "aquilo que, numa formação ideológica dada (...) determina o que pode e deve ser dito" e acrescenta que "as palavras, expressões, proposições etc., mudam de sentido segundo as posições sustentadas por aqueles que as empregam". Como Tereza "fala" a partir de duas posições distintas (catadora/escritora), podemos dizer que, dependendo da posição que ela "ocupa" (catadora ou escritora), os sentidos podem ser interpretados também diferentemente. Essas duas questões (condições de produção e formação discursiva) estão relacionadas ao controle do discurso no sentido de que o discurso só é "esse" em função da situaçãocontexto em que está inserido, e poderia ser (e provavelmente seria) outro se as condições de produção e a formação discursiva fossem também outras.

Nessa perspectiva, inserimos o conceito de posição-sujeito, que representa, no processo discursivo, as posições ocupadas pelos sujeitos dentro de uma determinada formação social. Ao falar em formação discursiva, Orlandi (2003:43) afirma que as palavras "tiram" seu sentido das posições que aqueles que as empregam ocupam em uma sociedade. Portanto, as posições-sujeito que Tereza ocupa em nossa formação social (catadora e escritora) irão 
determinar os sentidos de seu discurso, uma vez que, juntamente com as condições de produção e a formação discursiva, a posiçãosujeito exerce controle sobre esse discurso.

O modo como o sujeito significa em uma situação discursiva dada é afetado por dizeres já disponibilizados na memória desse sujeito, pelo que chamamos de interdiscurso. Definido por Pêcheux (1997: 162) como algo que " 'fala' sempre 'antes, em outro lugar e independentemente' ", o interdiscurso é o "lugar" em que o sentido foi constituído, ou seja, é aquilo que, ao significar "antes", possibilita seu sentido "agora". Aquilo que se diz (e faz sentido) agora, está na esfera da formulação, do intradiscurso, que Courtine (apud Orlandi, 2003: 33) define como "aquilo que estamos dizendo naquele momento dado, em condições dadas". Percebemos que há uma estreita relação entre o interdiscurso e o intradiscurso, uma vez que só é possível formular (intradiscurso) se nos colocarmos na esfera do dizível (interdiscurso). A isso Pêcheux, citado por Orlandi (2003: 33) acrescenta que "é o interdiscurso que especifica as condições nas quais um acontecimento histórico (elemento histórico descontínuo e exterior) é suscetível de vir a inscrever-se na continuidade interna, no espaço potencial de coerência próprio a uma memória".

Se partirmos do enunciado "Nós somos catadores (...) por falta de estudo", no qual Tereza conta como, há vinte anos, começou a catar papel, notaremos que aqui ela começa a significar o catar, (re)formulando um sentido já existente em sua memória, deixando implícito que, se tivesse estudado, não seguiria essa profissão. Partindo da afirmação de Achard (1999: 12) de que "o implícito trabalha (...) sobre a base de um imaginário que o representa como já memorizado", podemos dizer que Tereza retoma, através de sua afirmação, aquilo que, em outro momento, fez sentido para ela. Em outras palavras, ela utiliza o já-dito (interdiscurso) para formular o que está dizendo agora (intradiscurso), mas isso não equivale a dizer, como também coloca Achard (1999: 13), que "esse implícito (re)construído tenha existido em algum lugar como discurso autônomo", ou, ainda, que é essa a única interpretação possível desse enunciado. Quando Tereza afirma ser catadora "por falta de estudo" podemos apreender também, constitui-se o sentido de necessidade, se levarmos em consideração o contexto sóciohistórico de nosso país, no qual, sem estudo, não há emprego e, conseqüentemente, não há sustento. 
Em outra passagem do discurso da catadora/escritora, esse sentido torna-se ainda mais forte. Ao afirmar "eu estou catando as coisas que eu acho que devo de catar para ajudar na renda da minha família", Tereza significa o catar como fonte de renda. Podemos nos arriscar em dizer que, em sua memória (interdiscurso), ela tem constituída uma relação de significância que corresponde à equação catar = sustento.

Essa relação "vem à tona" no momento em que Tereza formula (intradiscurso) sua fala. Mas esse sentido só o é dentro dessas condições de produção, da formação discursiva dada e de acordo com a posição-sujeito ocupada por Tereza (catadora). É importante lembrarmos que os sentidos poderiam ser outros, visto que se movimentam de acordo com a ideologia da posição-sujeito de quem os significa e são ainda "controlados" pelas condições de produção e pela formação discursiva dominantes.

Ao dizer "eu não estou fazendo nada de errado", a catadora significa o ato de catar como correto, legal, honesto, dando um novo sentido à sua profissão. Acrescentamos então um novo elemento à nossa equação: catar $=$ sustento $=$ trabalho honesto. Além disso, ela (re)significa sua posição-sujeito catador ao colocar, em um de seus poemas, os seguintes versos "Vivo lidando com lixo/ Mas com muita honestidade". Podemos dizer que ela se utiliza do "falar em catar" para "falar de si" e significar-se como sujeito honesto.

Tereza faz emergir ainda um novo significado ao ato de catar, ao afirmar "eu não tenho problema e gosto, mas gosto mesmo", e movimenta assim o nosso imaginário sobre essa profissão. Antes, ser catador parecia-nos um trabalho "pesado", desagradável, mas, ao significá-lo como prazeroso, Tereza faz com que (re)formulemos nossos sentidos, ou seja, ao modificar o sentido em/para ela, faz com que também o modifiquemos em/para nós. Nossa equação, em que talvez nunca tenhamos pensado ao iniciarmos nossa interpretação, poderia ficar constituída da seguinte forma: catar = sustento $=$ trabalho honesto $=$ prazer .

Ao concluirmos os sentidos do catar para/em Tereza, passamos a nos concentrar nos significados que ela nos "apresenta" para 0 ato de escrever. Talvez seja apenas uma pretensão afirmarmos que "escrever" partiu de "catar", visto que, como diz Tereza "eu concretizei esse sonho dos meus dezessete anos". É certo que o sonho de ser escritora vem de muito antes de tornar-se catadora, mas no decorrer do seu discurso algumas afirmações de 
Tereza levam-nos a concluir que se não fosse catadora não chegaria a lançar um livro.

Ao falar em "sonho", quando coloca "eu concretizei esse sonho dos meus dezessete anos", percebemos que a catadora, agora também escritora, significava o ato de escrever, de lançar um livro, como algo distante de sua realidade, um desejo que se encontrava na esfera do irrealizável. Mas, quando afirma "concretizei", ela transfere aquilo que era apenas um "sonho", para a esfera do realizado. O sentido que Tereza tinha constituído para o ato de escrever em sua memória (interdiscurso) é agora (re)formulado no momento de sua fala e, é claro, "monitorado" pelas condições de produção e pela formação discursiva dadas.

Mas como chegamos ao gesto de interpretação em que "escrever" partiu de "catar"? Quando Tereza coloca "Aí eu vi que essa Irmã Lurdes Dill fez um convite para os catadores e catadoras que quisessem formar um Coral dos Catadores (...) foi onde surgiu a primeira poesia que o nome, O Convite, está no livrinho", notamos que ela volta a (re)significar o ato de escrever, do convite para entrar no coral, retorna o interesse pela poesia.

Aqui temos um primeiro indício dessa relação catar/escrever. Mas é quando Tereza fala "eu digo eu vou fazer uma poesia sobre a Casa de Cultura (...). Aí a Dona Regina, que é coordenadora disse: Tereza, quem sabe se nós fizéssemos um livrinho e lançava na Feira do Livro?' que podemos entender melhor como se interligam o ato de catar e o de escrever. Sendo a Dona Regina coordenadora do Coral dos Catadores e sendo através dela que Tereza lança seu livro, compreendemos que, se não fosse catadora, não faria parte do coral, não conheceria a Dona Regina e, conseqüentemente, não haveria realizado seu "sonho". Tereza tem consciência disso, tanto que afirma: "se eu não entrasse no coral e se eu não conhecesse a Irmã Dill, se eu não conhecesse a Dona Regina, se eu não conhecesse o Antônio Gringo (cantor nativista reconhecido pelo seu envolvimento em prol de causas sociais como a dos catadores), eu acho que as poesias iriam ficar guardadas e iria se tornar mais difícil'.

Até agora, não "vimos" Tereza falar a partir da posição-sujeito escritor, e sim a partir de uma posição-sujeito catador que lança um livro. Disso concluímos que as posições-sujeito que Tereza ocupa estão tão interligadas que nem ao menos ela consegue separá-las, ou seja, o sentido que Tereza tem constituído em sua memória "para 
ela mesma" está tão fortemente marcado que ela não consegue (re)formulá-lo.

Até mesmo no título de seu livro tem-se presente essa relação, uma vez que é o mesmo título do projeto realizado com os catadores pela Casa de Cultura de Santa Maria e, consequentemente, está relacionado com sua profissão. O primeiro momento em que Tereza posiciona-se como escritora é em "e quando eu saio pra catar, eu levo eles junto (os livros) porque, no meu carrinho eu botei na frente, Catando cidadania, autora de Catando cidadania". Ao se colocar como "autora de Catando Cidadania", Tereza, é claro, assume sua posição-sujeito escritor, mas, ainda assim, ela não "dissolve" a relação que essa posição possui com sua posição-sujeito dominante (a posição-sujeitocatador).

\section{Considerações finais}

Na primeira etapa de nossa interpretação, quando tentamos entender o sentido do catar para/em Tereza, e como ela significa sua posição-sujeito catador, pudemos observar que não existe um sentido apenas, fechado em si mesmo, mas que esses são múltiplos, e vão se constituindo no momento em que Tereza fala, de acordo com a posição-sujeito catador assumida por ela, com o momento histórico pelo qual passamos (momento em que se institui a profissão catador) e com o contexto imediato em que se realizou seu discurso (época do lançamento de seu livro).

Além disso, através de nosso gesto de interpretação chegamos à nossa equação e entendemos como esses sentidos estão relacionados entre si. Parece-nos que eles estão envolvidos em um movimento espiral que não permite cortarmos sua ligação, é como se estivessem contidos um dentro do outro e, todos eles, contidos no catar que Tereza nos "revela".

Outra questão que parece estar "amarrada" em seus sentidos é a relação entre catar e escrever. Ao longo de nossa interpretação, fomos tentando "separar as peças" e "significá-las" separadamente, mas cada vez mais elas se entrelaçavam, o que nos levou a concluir que escrever partiu de catar e que, além de não podermos significar Tereza apenas como catadora (mas também como escritora), igualmente não podemos falar da escritora sem citarmos a catadora.

Ao percebermos o quanto catadora e escritora estão interligadas, atentamos para o fato de que talvez não possamos 
falar, no que toca à Tereza, de posição-sujeito catador e posiçãosujeito escritor, visto que Tereza não assume as duas posições, mas apenas a primeira. Como já dissemos, em nosso entender, isso se deve ao fato da "imagem" que ela tem de si mesma, que foi construída ao longo de vinte anos de trabalho, estar tão bem constituída, compreendida e "internalizada" na memória de Tereza, que nem ela, nem qualquer "outro" possa modificá-la.

A relação entre as duas "identidades" de Tereza se dá, portanto, de forma que não podemos interpretá-las separadamente e que, para/em Tereza, elas são uma identidade única, que se expressa através de uma posição-sujeito catador, mas uma posiçãosujeito catador que agora tem um livro lançado na Feira do Livro de Santa Maria, cidade com a designação de cidade universitária.

\section{Referências bibliográficas}

ACHARD, Pierre et al. Papel da Memória. São Paulo: Pontes, 1999. FOUCAULT, Michel. A Ordem do Discurso. 7. ed. São Paulo: Loyola, 2001.

ORLANDI, Eni Puccinelli. Análise de Discurso: princípios \& procedimentos. 5. ed. Campinas, SP: Pontes, 2003.

PÊCHEUX, Michel. Semântica e Discurso: Uma Crítica à Afirmação do Óbvio. 3. ed. Campinas, SP: Editora da Unicamp, 1997. 